\title{
New York enacts surrogate decision-making legislation for incapacitated patients
}

Published at www.cmaj.ca on Apr. 13

I $\mathrm{t}$ was 17 years in the making, but the state of New York has become the latest to enact legislation setting out who makes health care decisions for patients incapable of making their own.

The Family Health Care Decisions Act establishes a hierarchy of "surrogate" decision-makers, with courtappointed guardians sitting atop the list, followed by spouses and domestic partners, children, parents, siblings and close relatives or friends.

The legislation allows surrogates to make health care decisions on behalf of patients who have lost their capacity to do so and did not leave advance directives regarding the withdrawal of life-sustaining treatment. They cannot be appointed until the attending physician determines that the patient lacks decision-making capacity.

The legislation contains safeguards against "inappropriate" decisions, however, including procedures for family members or physicians to object to the choice of surrogate or to a surrogate decision. The law also does not apply to those who have developmental disabilities, or who reside in mental health facilities.

The law, signed by New York governor David Paterson on Mar. 16, applies in situations when a decision must be made regarding the use of such things as ventilators, feeding tubes or antibiotics for patients who are dying, unconscious, brain damaged or suffering from dementia.

According to the law, a surrogate is to consider the patient's wishes, including religious and moral beliefs, in making a health care decision. If no written instructions exist and those wishes cannot otherwise be established, the "best interests" of the patient are to guide decision-making.

A surrogate may withhold or with-

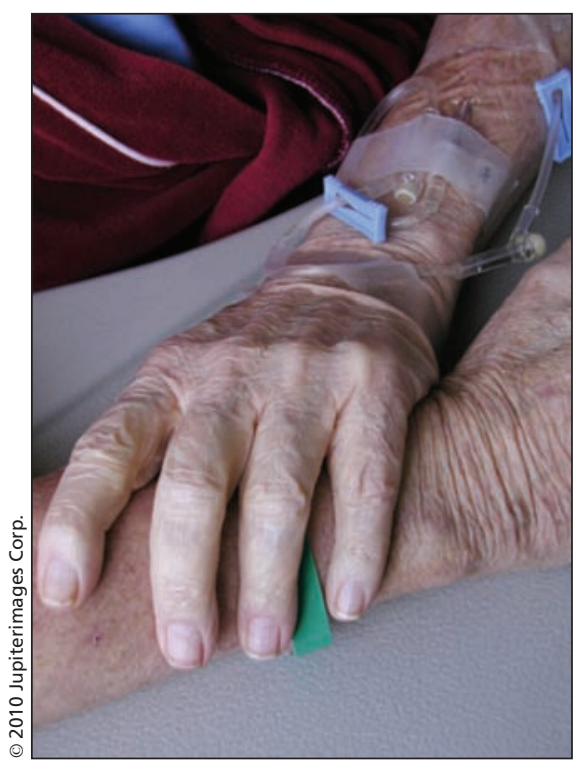

New York's Family Health Care Decisions Act establishes a hierarchy of "surrogate" decision-makers for incapacitated patients, with court-appointed guardians sitting atop the list, followed by spouses and domestic partners, children, parents, siblings and close relatives or friends.

draw life-sustaining treatment for an individual if it "would be an extraordinary burden to the patient" and if the patient "has an illness or injury which can be expected to cause death within six months, whether or not treatment is provided," the act states.

As well, a surrogate may withhold or withdraw life-sustaining treatment if the patient has an "irreversible condition," as determined by two independent physicians, and treatment would involve "such pain, suffering, or other burden that it would be inhuman or extraordinarily burdensome to provide treatment under the circumstances."

New York joins several other states in specifying a hierarchy of surrogates, according to the American Medical Directors Association. But there's a widespread variation in how states handle such situations and some don't have a decision-makers list, although everyone in the United States is guaranteed the right to refuse or discontinue treatment under 1991 federal legislation, The Patient Self-Determination Act, which also makes advance directives completed in any state legal and portable.

The American Medical Directors Association says that decisions of surrogates are typically guided by "substituted judgement (if the incapacitated person's wishes were known but not formalized in an advance directive), [and the] best interest of the patient, based on clinical evidence, prognosis, life expectancy risk and benefit of proposed treatments, comfort and dignity" (www .amda.com/governance/whitepapers/sur rogate/decisionmaking_hierarchy.cfm).

This is how it works in most Canadian hospitals as well, says Margaret Somerville, founding director of the McGill Centre for Medicine, Ethics and Law in Montréal, Quebec.

"The principal way this is dealt with is that if you don't give advanced directives, substituted judgment is used," says Somerville. "In the absence of substituted judgment, you consider best interests."

In Canada, provinces are responsible for determining who is designated a surrogate for an incapacitated patient. Article 15 of Civil Code of Quebec, for instance, states that in the absence of a designated surrogate, "consent to care" is given by the patient's "married, civil union or de facto spouse or, if the person has no spouse or his or her spouse is prevented from giving consent, it is given by a close relative or a person who shows a special interest in the person of full age."

In most situations, a surrogate can be easily identified, but not always.

"In a situation with no surrogate, it can be challenging," says Dr. Doreen Oneschuk, a palliative medicine physician at the Grey Nuns Community Hospital in Edmonton, Alberta. "The 
physician is put in that role and it many not be clear what the patient's wishes were."

Even if the patient's wishes are known, however, doctors take into account many other factors, according to a recent survey of 281 physicians, including internists, family doctors and intensive care unit physicians (JAGS 2010;58:533-8). Of the 73.3\% of respondents who recently made a surrogate decision, only $29.4 \%$ claimed that patient preference was the principal deciding factor. Roughly $33 \%$ reported that doing "what was best for the patient overall" was most important, while $13 \%$ first considered "the patient's pain and suffering" and $12 \%$ considered "the patient's prognosis."

"The presence of a living will, prior discussions with the patient, and the physicians' beliefs about ethical guidelines did not significantly predict the physicians' reliance on patient preferences," the authors concluded.

In about $90 \%$ of cases, however, the doctor will not have to act as surrogate, according to a 2009 survey of 281 doctors (J Gen Intern Med 2009;24:1023-8). The survey also found that conflict between doctors and surrogates is rare, occurring in only $5 \%$ of cases, though one in five doctors reported they were uncomfortable dealing with surrogates. In about a fifth of cases, physicians reported having trouble contacting surrogates.

"Surrogate decision making is common among hospitalized adults," the authors stated. "Physician-surrogate decision making may be enhanced if patients discuss their preferences in advance and if physician contact with surrogate decision makers is facilitated."

Planning your care in advance is particularly important, says Oneschuk, though too few patients do so. "It's an area that deserves more attention," she says. "It would make it easier for health care providers." — Roger Collier, CMAJ

DOI:10.1503/cmaj.109-3229 